\title{
Sexual Behaviour Problems : Current State of Knowledge and Representations by Medico-Social Professionals in France
}

Charlie Simon ( $\nabla$ charlie.simon1@etu.univ-lorraine.fr)

Centre Psychotherapique de Nancy-Laxou: Centre Psychotherapique de Nancy https://orcid.org/00000001-6632-5033

\section{Morgane Ulrich}

University of Lorraine: Universite de Lorraine

\section{Baptiste Oriez}

Centre de Ressources pour les Intervenants auprès des Auteurs de Violences Sexuelles de Lorraine

\section{Charlotte Demonte}

Centre de Ressource pour les Intervenants auprès des Auteurs de Violences Sexuelles de Lorraine

\section{Pierre Horrach}

Centre Psychotherapique de Nancy-Laxou: Centre Psychotherapique de Nancy

\section{Fabienne Ligier}

PUPEA centre psychotherapique de Nancy

\section{Research article}

Keywords: psycho-sexual and emotional development, sexual behaviour problems, child professionals, institution

Posted Date: November 13th, 2020

DOI: https://doi.org/10.21203/rs.3.rs-104716/v1

License: (a) (1) This work is licensed under a Creative Commons Attribution 4.0 International License. Read Full License 


\section{Abstract}

\section{Background}

There are no studies identified that address professionals' knowledge of sexual behaviour problems in children aged 0-12 years. However, it seems essential for child professionals to be able to identify the healthy or pathological nature of sexual behaviour.

\section{Case presentation}

We proposed a cross-sectional, descriptive and comparative observational study using anonymous questionnaires distributed to medico-social professionals in France. They were questioned on their knowledge of normal sexual development, risk factors for developing sexual behaviour problems, and the future of minors presenting these behaviours.

\section{Conclusions}

Among the 93 respondents whose questionnaires were usable, there were 12 men and 81 women. The majority of respondents didn't know the age at which psychosexual and emotional child development begins $(73.1 \%)$ or didn't know the age limits for sexual behaviour problems $(95.7 \%)$. Very often, these professionals represented children with sexual behaviour problems as "children who have been abused" (81.72\% of respondents) and/or who "will become child perpetrators of sexual violence" $(70.87 \%$ of respondents). All these answers highlight the lack of training of these professionals, at the risk of proposing a reply that is not adapted to children with these disorders. So, it seems essential to offer more systematic and adapted courses to professionals who take care of minors in institutions.

\section{Background}

Sexual behaviour problems (SBP) in children don't have a universal definition. It is generally accepted that SBP are neither a mental health disorder nor a diagnosis, but rather behaviour manifestations on the margins of healthy sexual development. The working group of the Association for the Treatment of Sexual Abusers (ATSA)(1) proposed a definition in 2008 that has been used by many authors. It concerns "children ages 12 and younger who initiate behaviours involving sexual body parts (i.e. genitals, anus, buttocks or breasts) that are developmentally inappropriate or potentially harmful to themselves or others. Although the term sexual is used, the intentions and motivations for these behaviours may or may not be related to sexual gratification or sexual stimulation. The behaviors may be related to curiosity, anxiety, imitation, attention-seeking, appeasement, or other reasons". Furthermore, "sexual behaviour problems (SBP) don't represent a medical/psychological syndrome or a specific disorder, but rather a set of behaviors that are outside acceptable societal limits". Some authors have established a classification which is a continuum between healthy and pathological development that should be distinguished for a better understanding of child development(2),(3). They emphasise the importance of understanding and being able to assess minors in terms of psychosexual and emotional development(4). 
In terms of the prevalence of SPB: in the field of child protection, 10 to $30 \%$ of children in the United States, (5), (6) and approximately 15\% in Quebec, (7), (8) are thought to have SBP. In France, there are no epidemiological studies targeting sexual behavior problems.

In terms of care, children with SBP do not always benefit from therapies adapted to their problems, (3), (5), (8) whereas cognitive-behavioral therapies centered on the minor with the participation of families/guardians/care providers are efficient. These children are sometimes even considered by professionals as future offenders, which can have an impact on their development and care. (9)

Since the 1990s, researchers have been interested in SBP on an etiological side. For some, having been sexually assaulted is the main risk factor for developing SBP, as it is for adult perpetrators of sexual violence (10). For others, SBP are not related to a history of sexual abuse (4). The development of SBP appears to follow multiple and complex trajectories (3), revealing multiple individual and familial risk factors. Children may thus present cognitive and language deficits, behavioural disorders, have witnessed domestic violence, been victims of sexual assault, physical abuse, psychological abuse or have grown up with parents who presented substance abuse or experienced psychological distress(3),(11).

In France, children in medical or social care institutions may have a life history already marked by emotional and educational deficiencies. When these children present SBP, they sometimes cause worries to professionals who do not always know how to identify and evaluate these disorders, and even less how to react to them, according to the literature (12) and the clinical experience of the professionals of the CRIAVS (Centre de Ressource et d'intervention pour les auteurs de violences sexuelles).

The lack of French epidemiological data associated with the potential difficulties of professionals to identify and reply to SBP led us to conduct a descriptive observational study with the main objective of "describing, based on self-questionnaires completed by medical, health and social professionals working with children under 12 years of age in France, the current state of knowledge and representations related to SBP in this population".

The results of this study could be used to offer training to professionals, including tools for the care of children with SBP if needs of this kind are identified.

\section{Case Presentation}

\section{Methods}

We conducted a cross-sectional, descriptive and comparative observational study.

\section{Objectives of the study}

The main objective was to make an inventory of knowledge and representations related to SBP, based on self-questionnaires filled in by medical, health and social professionals working with children under 
12 years old in Meurthe-et-Moselle, France.

The secondary objectives were to analyse the practice of professionals in institutions regarding SBP and child sexuality and to investigate factors influencing the type of practice. The results of this second objective will not be presented in this study and are the subject of another manuscript.

\section{Target population}

We targeted professionals in medical and social structures of Meurthe-et-Moselle that care for children aged $0-12$ years with cluster randomization by type of institution.

For this purpose, we have elaborated an exhaustive list of these institutions based on two websites: annuaire.action-sociale.org and creai-grand-est.fr. In total, 182 structures have been listed in the territory of Meurthe-et-Moselle. We classified the institutions into large subgroups (16 subgroups) and then proceeded to draw lots within each subgroup in order to select 2 to 3 institutions per subgroup and to select 36 in total.

The e-mail addresses of the directors and managers of these randomly selected organisations were collected by telephone. After explaining the objectives of our study and after an agreement, the link to the questionnaire was given to the managers of the structures who then distributed it to their teams.

The questionnaire was published on the Drag'nSurvey® site (questionnaire available on request). For data collection, we chose to collect data by online response only, for feasibility reasons and due to the health crisis situation related to COVID-19. The questionnaire was accessible from March 25, 2020 to May 25, 2020. A systematic follow-up was carried out after three weeks.

According to the public health code, no prior authorization was required to carry out this study, which was intended for a voluntary, healthy public whose answers were completely anonymous.

\section{Collected data}

All data were collected from the self-questionnaire, which was anonymous in order to reduce social desirability bias.

In the French literature, there was no measurement tool available to meet the objectives of the study, so we had to develop a tool consisting of 27 open-ended and close-ended questions (single choice, multiple choice). The themes addressed are the identification of SBP and the support offered to the children. The questionnaire was written based on knowledge from the current literature, mainly American and Canadian, and current recommendations on the subject.

The questions were developed trying to provide as little information as possible so as to not influence respondents in their choice of answers. It was not possible to return to the previous questions.

The self-questionnaire is composed of 27 items, grouped into 4 parts: 
- The first part (questions 1 to 6 ) focuses on the socio-demographic characteristics of professionals (gender, profession, number of years of practice and type of practice institution, number and age range of children in care);

- The second part (questions 7 to 11) deals with the knowledge of professionals about PSED. In question 8 , we gave several examples of behaviours to be qualified as either healthy sexual behaviours or problematic sexual behaviours. Questions 10 and 11 focus on professionals' knowledge of SBP and their interpretation of them.

Between the second and third parts, the Atsa Task Force's definition of SBP is provided to ensure that all participants could understand the difference between healthy sexual behaviours and SBP: "Behavior involving sexual parts of the body, initiated by children $0-12$ years of age, that is developmentally inappropriate or potentially harmful to the child or others. These behaviours are motivated by curiosity, anxiety, imitation, attention-seeking, appeasement, etc. Sexuals behaviors problems occur regularly, are not mutual and are coercive when they involve other children, the behavior itself can cause emotional distress."

- The third part (questions 12 to 20) follows this definition and collects data on children with SBP that they would have encountered at their place of practice (number, types, psychiatric co-morbidities, becoming children with SBP). It also aims to provide an update on the care of these children and to invite participants to share their feelings.

- The fourth part (questions 21 to 27) concerns the level of management and tolerance of child sexuality as well as the legal framework set by the administration of their institution. Questions 26 and 27 focus more specifically on the training professionals received on SBP.

The third and fourth parts concern secondary objectives.

The questionnaire was tested on 12 professionals practicing in two child psychiatry institutions to ensure a good understanding of the questions, which could be modified if necessary. The response time was estimated at 20 to 30 minutes.

We obtained 136 respondents to the questionnaire at the end of the data collection period. After reviewing the various respondents, we chose to exclude those who had answered fewer than 12 questions, which corresponds to approximately $50 \%$ of the total number of questions, in order to ensure the reliability and continuity of the responses. Then we excluded respondents who mentioned working only with children aged 13 and over (cf target population). This left a total of 93 usable responses out of the 136 received, or approximately $68.4 \%$ of the questionnaires received.

\section{Data Analysis}

The data was collected and analysed via the Excel® spreadsheet after numerical coding.

We described the quantitative data by their mean and standard deviation and qualitative data by their absolute number and percentage. 


\section{Results}

Study population

Of the 93 respondents whose questionnaires were usable, there were 12 men and 81 women.

Knowledge about PSED and SBP without introductory information

Representations, by professionals:

- of the age at which the child begins to be accompanied to the PSED are presented in Fig. 1.

- of the age concerned by SBP in Fig. 2.

Figure 3 shows the representations of professionals regarding SBP and the children who present some.

Thus, $69.90 \%$ of respondents believe that SBP can appear in adulthood. $81.72 \%$ of professionals make a link between SBP and having been a victim of sexual violence and $70.9 \%$ think that children with SBP are more at risk of becoming sexual abusers. Furthermore, $27.96 \%$ of respondents attribute to children with SBP an underlying psychiatric pathology that causes these behaviours.

Evaluation of situations proposed in the questionnaire

In Fig. 4, the expected responses are those represented by the orange line, with the professionals' responses to the assessment of various situations shown in the blue line.

Legend:

a: At the age of 9 months, have an erection at the time of change a diaper

b: At the age of 3 years old, insert your finger into the sexual orifice of another child

c: At the age of 2 years old, lay your head on the genitals of a clothed adult

d: At the age of 3 years old, try to see your parents naked

e: At the age of 4 years old, practice sexual games such as "the Doctor" or "daddy-mommy" with exploration of the other person's body or private parts

$f$ : At the age of 5 years old, showing off in front of others

g: At the age of 7, masturbate several times a day

h: At the age of 8 years old, making crude sexual comments

i: At the age of 10 , ask yourself about your sexual orientation

$\mathrm{j}$ : At the age of 12, caressing the sexual parts of an animal

k: A At the age of 14 , have already had a homosexual experience (kisses, caresses, sexual relations...) Evaluation of representations and SBP after the proposed definition 
According to this definition, out of 87 respondents, only 12 (13.79\%) were able to indicate that they had never been confronted with a minor with SBP.

Of the 75 who said they had experienced one or more minors with SBP in the previous year:

- 57 (65.52\%) had met between 1 and 4 minors.

- $10(11.49 \%)$ had met with 5 to 9 minors.

- 4 (4.60\%) had met between 10 and 14 minors.

- 3 (3.45\%) had met between 15 and 20 minors.

- $1(1.15 \%)$ had met more than 20 minors.

\section{Discussion}

For more than twenty years, several studies have demonstrated the interest to differentiate early behaviours belonging to a child's normal PSED and SBP in order to intervene effectively and reduce this phenomenon. (12), (13), (14)

Our study uncovered various elements that reveal a lack of training and information for professionals working with children in institutions.

First of all, almost $3 / 4$ of the medico-social professionals interviewed do not know the age at which support to the child's psychosexual and emotional life begins. Sexual and emotional support should begin at the youngest age of the child, from 0 to 3 years old (4), (12).

Only $26.9 \%$ of respondents held this notion.

However, it seems essential for professionals to know the basics of healthy sexuality in relation to the age and development of the child in order to be able to identify SBP.

The 11 clinical situations that we suggested to respondents corroborate professionals' lack of knowledge about PSED, since approximately one-third of them are not judged as they should be (Fig. 4).

The ATSA(1) definition of SBP states that the term applies to children aged $0-12$ years. Only $4.3 \%$ of participating professionals are aware of this age limit (Fig. 2). In addition, $69.9 \%$ of respondents even think that problematic sexual behaviour can appear in adulthood (Fig. 3). This shows us the extent to which professionals are unclear about the definition of SBP, which has implications for the care of children with SBP. It is easy to imagine that ignoring this definition would quickly put the sexual behaviour of a 16-year-old teenager on the same level as that of a much younger child. On the other hand, the term "problematic sexual behaviours" is very little known and used in medical-social institutes: it is even frequently misused to explain sexual behaviours of adults. This is most certainly why, in our study, some people working only with adults still answered the questionnaire. 
Furthermore, the responses also revealed a certain stigmatisation of children with SBP. During the 1980s and 1990s, children with SBP were automatically labelled as victims of sexual abuse and future aggressors, as already presented in the introduction (3), (4), (10). The consequence of this stigmatisation is that these children are excluded, mistrusted and even avoided rather than offered care. In our study, it is quite obvious that the representation "abused child $=>$ child with SBP $=>$ abusive child" is very present in people's minds since the majority of professionals who responded believe that minors with SBP have been sexually abused $(81.72 \%)$ and that these children are more at risk of being perpetrators of sexual violence (70.97\%). However, considering children with SBP as future sexual abusers at an early age necessarily interferes with the care offered to them (9). According to the literature, (4), (15) children with SBP are at greater risk of becoming perpetrators of sexual violence when no action is taken to understand and stop SBP. Again, this study highlights the lack of knowledge on this topic.

\section{Strengths and weaknesses}

The interest of this study is its originality since, to our knowledge, it is unique in France.

However, it has certain limitations. Due to the lack of existing data, we had to carry out a de novo questionnaire which is not validated and which may have some flaws. For example, it is possible that even when presented in writing, the definition of SBP may not have been fully understood because it is composed of rather complex terms. Furthermore, because of the computer tool used, we had to propose at least 3 choices of answers, which forced us to put a "void" item for question 8 , an item that some people still retained, which prevented them from choosing one of the 2 answers, and which generated missing data, fortunately of low volume.

As in any questionnaire targeting a sensitive subject and involving the respondents' professional practices, there may have been a desirability bias that we have tried to reduce as much as possible by not asking for any data that would allow us to remove the respondents' anonymity. In addition, we cannot be certain that the respondents are representative.

We also note the possibility of representativeness bias and we cannot extrapolate the results to all medico-social professionals in France.

\section{Conclusion}

This study revealed that the problem of SBP was not well known by most professionals working with children, and the child sexuality was not understood. Therefore, before even talking about care, it would be judicious to train all professionals working with children in children's PSED. Under these conditions, they could acquire knowledge and tools to understand and discern a "normal" sexual attitude from the "problem".

Our data are corroborated by recommendations in the literature (1), (3), (12), (16), (17), (18), (9) and highlight the value of learning about PSED to better identify SBP. 
As a second step, a practical, multi-professional approach to children with SBP could be taught, which could include:

- The approach to take with minors with SBP

- Active and direct involvement of caregivers (current and future) in treatment

- The importance of involving families/guardians in the care (biological parents, foster parents, or nonabusive relatives)

- The inclusion of psychoeducation and Cognitive Behavioral Therapy (CBT) for the direct management of sexual behaviour.

It would also be interesting to carry out a survey on the representations of SBP of a broader spectrum on the French territory in order to compare the results obtained.

\section{Abbreviations}

SBP

Sexual behaviour problems

PSED

psychosexual and emotional development

ATSA

Association for the Treatment of Sexual Abusers

\section{Declarations}

1. Ethics approval and consent to participate

According to the Public Health Code, no prior authorization was required to carry out this study, which was intended for a voluntary, healthy public whose answers were completely anonymous.

2. Consent for publication

All personal data has been made anonymous.

3. Availability of data and materials

The data sets used and/or analysed in this study are available from the corresponding author upon reasonable request.

4. Competing interests

The authors declare that they have no competing interests.

5. Funding 
No funding to report.

\section{Authors' contributions}

CS participated in the writing of this article, the drafting of the questionnaire, the analysis of the data and the necessary bibliographical research.

MU participated in the writing of this article, the drafting of the questionnaire, the analysis of the data and the necessary bibliographical research.

BO participated in the writing of this article, the drafting of the questionnaire and the necessary bibliographical research.

CD participated in the writing of this article, the drafting of the questionnaire and the necessary bibliographical research.

$\mathrm{PH}$ participated in the writing of this article, the drafting of the questionnaire, the analysis of the data and the necessary bibliographical research.

FL participated in the writing of this article, the drafting of the questionnaire, the analysis of the data and the necessary bibliographical research.

All authors have read and approved the final manuscript.

7. Acknowledgements

Not applicable

\section{References}

1. Chaffin M, Berliner L, Block R, Johnson TC, Friedrich WN, Louis DG, et al. Report of the ATSA Task Force on Children With Sexual Behavior Problems. Child Maltreat. mai 2008;13(2):199-218.

2. Essa EL, Murray Cl. Sexual Play: When Should You Be Concerned? Child Educ. juin 1999;75(4):231-4.

3. St-Amand A, Villeneuve M-P, Vaillancourt A. Les comportements sexuels problématiques chez les enfants: pistes de réflexion pour une pratique en émergence. Serv Soc. 6 juin 2017;63(1):55-72.

4. Johnson TC. Some Considerations About Sexual Abuse and Children with Sexual Behavior Problems. J Trauma Dissociation. sept 2002;3(4):83-105.

5. Baker AJL, Schneiderman M, Parker R. A Survey of Problematic Sexualized Behaviors of Children in the New York City Child Welfare System: Estimates of Problem, Impact on Services, and Need for Training. J Child Sex Abuse. 18 juin 2002;10(4):67-80.

6. Szanto L, Lyons JS, Kisiel C. Childhood Trauma Experience and the Expression of Problematic Sexual Behavior in Children and Adolescents in State Custody. Resid Treat Child Youth. juill 2012;29(3):231-49. 
7. Lepage J. Comportements sexuels problématiques d'enfants pris en charge par les Centres jeunesse: facteurs associés. [Ottawa]: Library and Archives Canada = Bibliothèque et Archives Canada; 2009.

8. Dufour C, Tougas A-M, Tourigny M, Paquette G, Hélie S. PROFIL PSYCHOSOCIAL DES ENFANTS PRÉSENTANT DES COMPORTEMENTS SEXUELS PROBLÉMATIQUES DANS LES SERVICES QUÉBÉCOIS DE PROTECTION DE L'ENFANCE. Can Soc Work Rev. 29 août 2017;34(1):23-45.

9. Banbury S-A. Working with Children with Sexual Behavior Problems, by Jan Eliana Gil and Jennifer A. Shaw. J Child Sex Abuse. 3 oct 2014;23(7):861-3.

10. Hanson RK, Slater S. Sexual Victimization in the History of Sexual Abusers: A Review. Sex Abuse J Res Treat. 1 janv 1988;1(4):485-99.

11. Boisvert I, Tourigny M, Lanctôt N, Lemieux S. Comportements sexuels problématiques chez les enfants: une recension systématique des facteurs associés. Rev Psychoéducation. 17 mars 2017;45(1):173-207.

12. Gagnon MM, Tremblay $\mathrm{C}$, Bégin $\mathrm{H}$. Intervention de groupe auprès d'enfants présentant des comportements sexuels problématiques: évolution comportementale, affective et sociale. Santé Ment Au Qué. 25 janv 2006;30(2):257-79.

13. Pithers WD, Gray A, Busconi A, Houchens P. Caregivers of children with sexual behavior problems: Psychological and familial functioning. Child Abuse Negl. févr 1998;22(2):129-41.

14. Ryan G. Childhood sexuality: a decade of study. Part II-dissemination and future directions. Child Abuse Negl. janv 2000;24(1):49-61.

15. Bernard A. «On a oublié de parler de quelque chose» : les agirs sexuels d'enfants comme psychopathologie de la vie quotidienne des institutions. Rev Psychothérapie Psychanal Groupe. 2018;71(2):127.

16. Friedrich WN, Bakery AJL, Parker R, Schneiderman M, Gries L, Archer M. Youth with Problematic Sexualized Behaviors in the Child Welfare System: A One-Year Longitudinal Study. :16.

17. Silovsky JF, Niec L, Bard D, Hecht DB. Treatment for Preschool Children With Interpersonal Sexual Behavior Problems: A Pilot Study. :15.

18. Friedrich WN, Fisher J, Broughton D, Houston M, Shafran CR. Normative Sexual Behavior in Children: A Contemporary Sample. Pediatrics. 1 avr 1998;101(4):e9-e9.

\section{Figures}




\section{What is the age at which to start psychosexual and emotional support?}

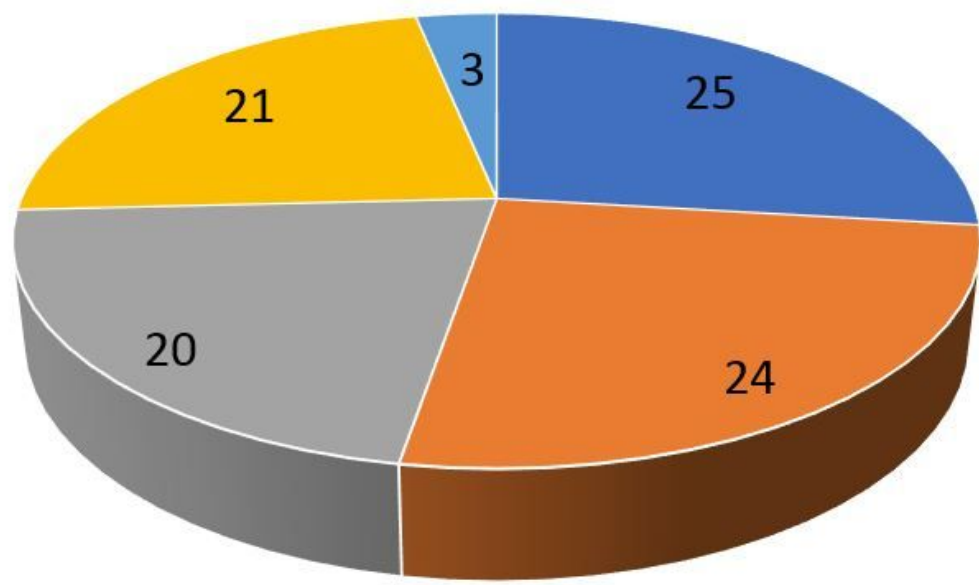

- 0 to 3 years $\quad 3$ to 6 years $\quad 6$ to 9 years $\quad 9$ to 12 years 12 to 15 years

Figure 1

Professional representation for the age of the beginning of PSED support $(n=93)$ 


\section{What is the age at which to start psychosexual and emotional support?}

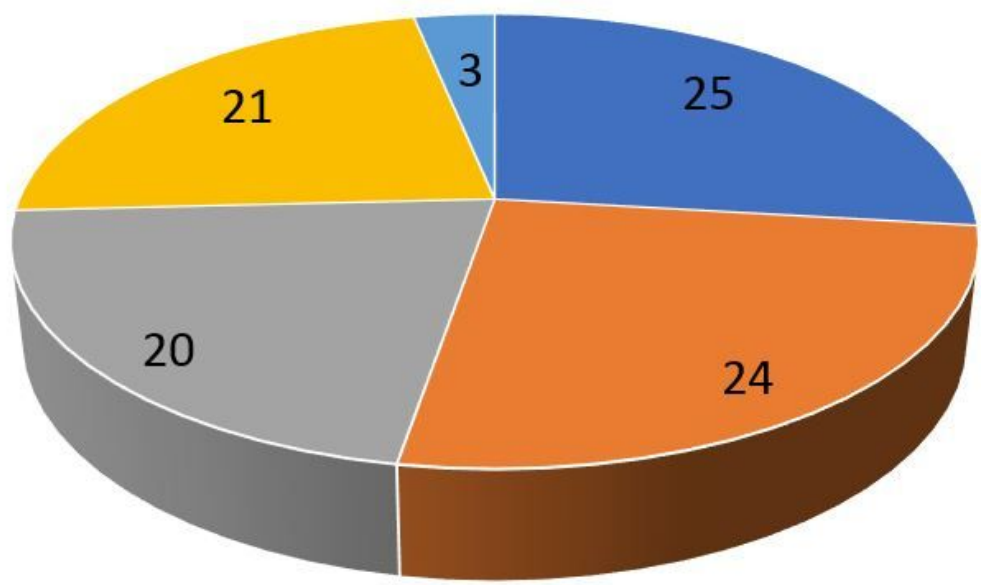

- 0 to 3 years $\quad 3$ to 6 years $\quad 6$ to 9 years $\quad 9$ to 12 years 12 to 15 years

Figure 1

Professional representation for the age of the beginning of PSED support $(n=93)$ 


\section{What is the age at which to start psychosexual and emotional support?}

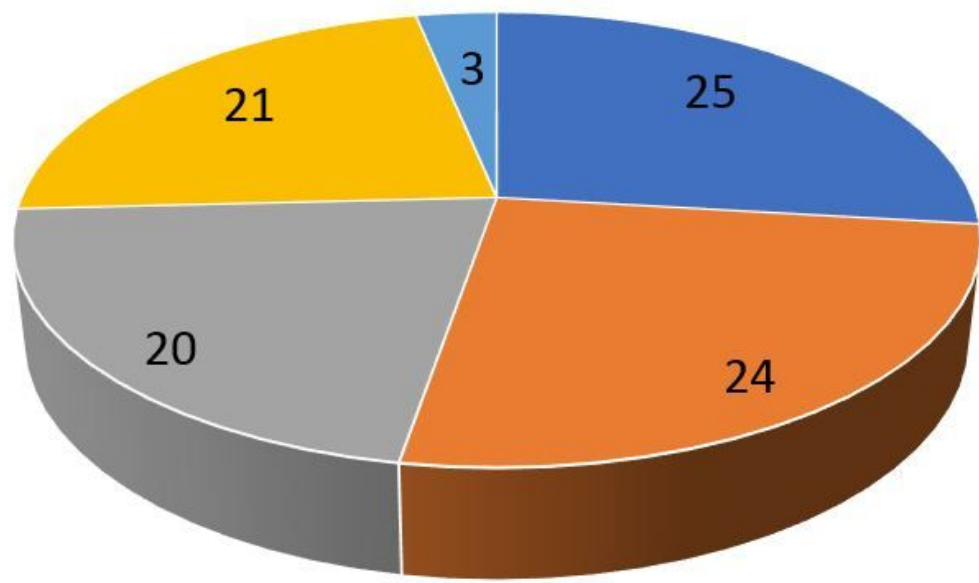

- 0 to 3 years $\quad 3$ to 6 years $\quad 6$ to 9 years $\quad 9$ to 12 years $\| 12$ to 15 years

\section{Figure 1}

Professional representation for the age of the beginning of PSED support $(n=93)$

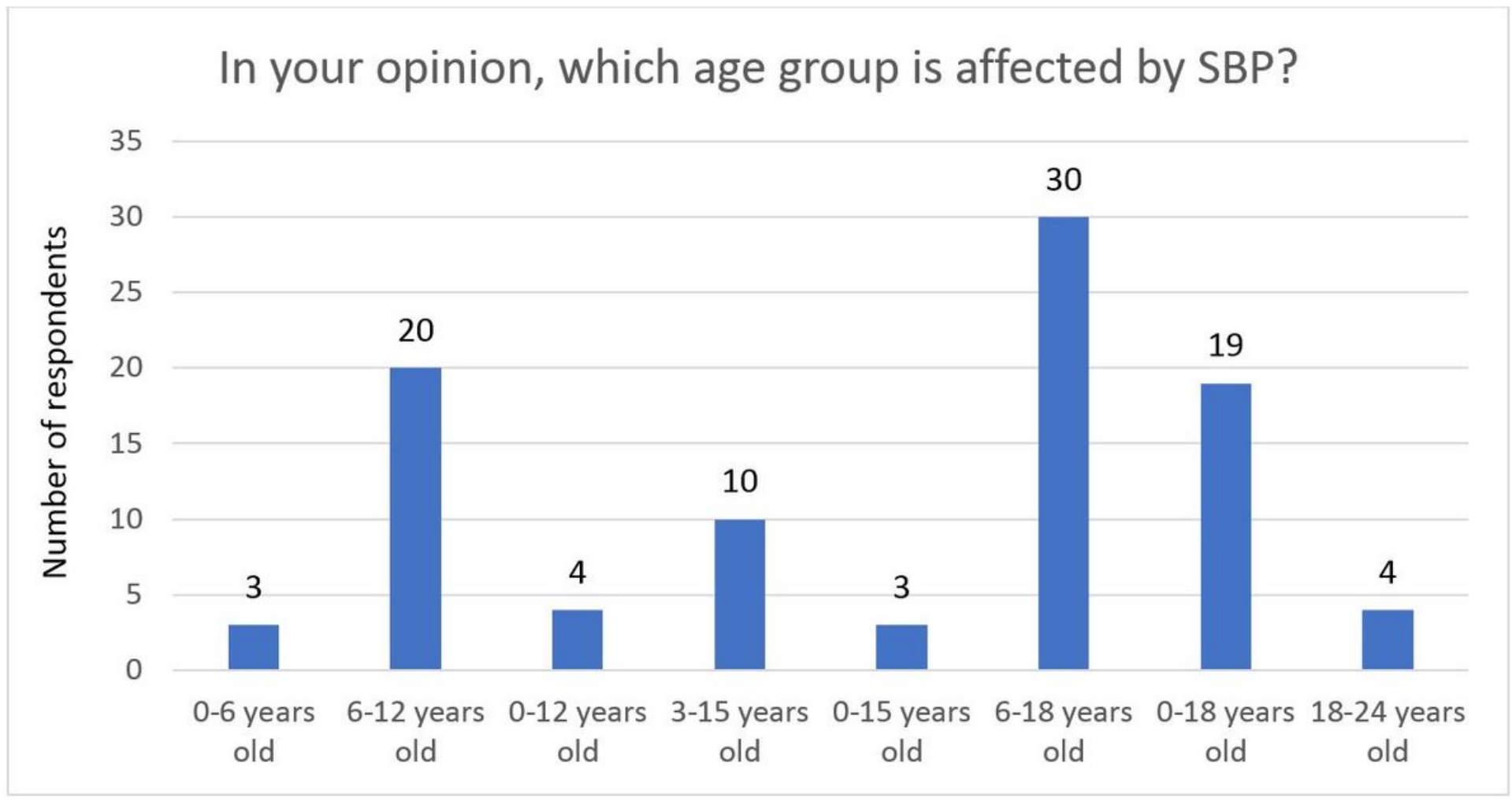


Figure 2

Representation by Professionals for the Age Group of Children Involved by SBP ( $n=93)$

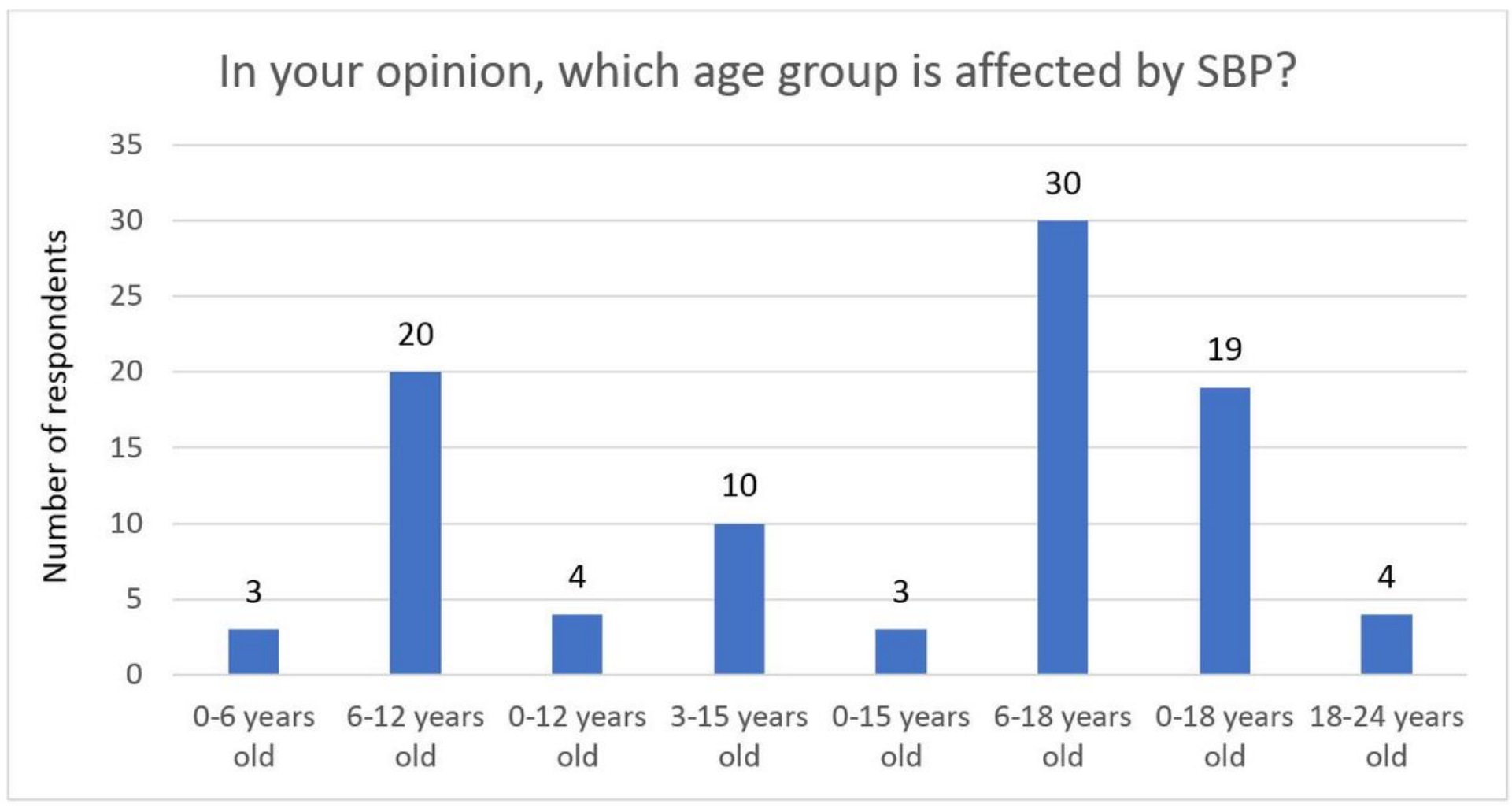

Figure 2

Representation by Professionals for the Age Group of Children Involved by SBP $(n=93)$

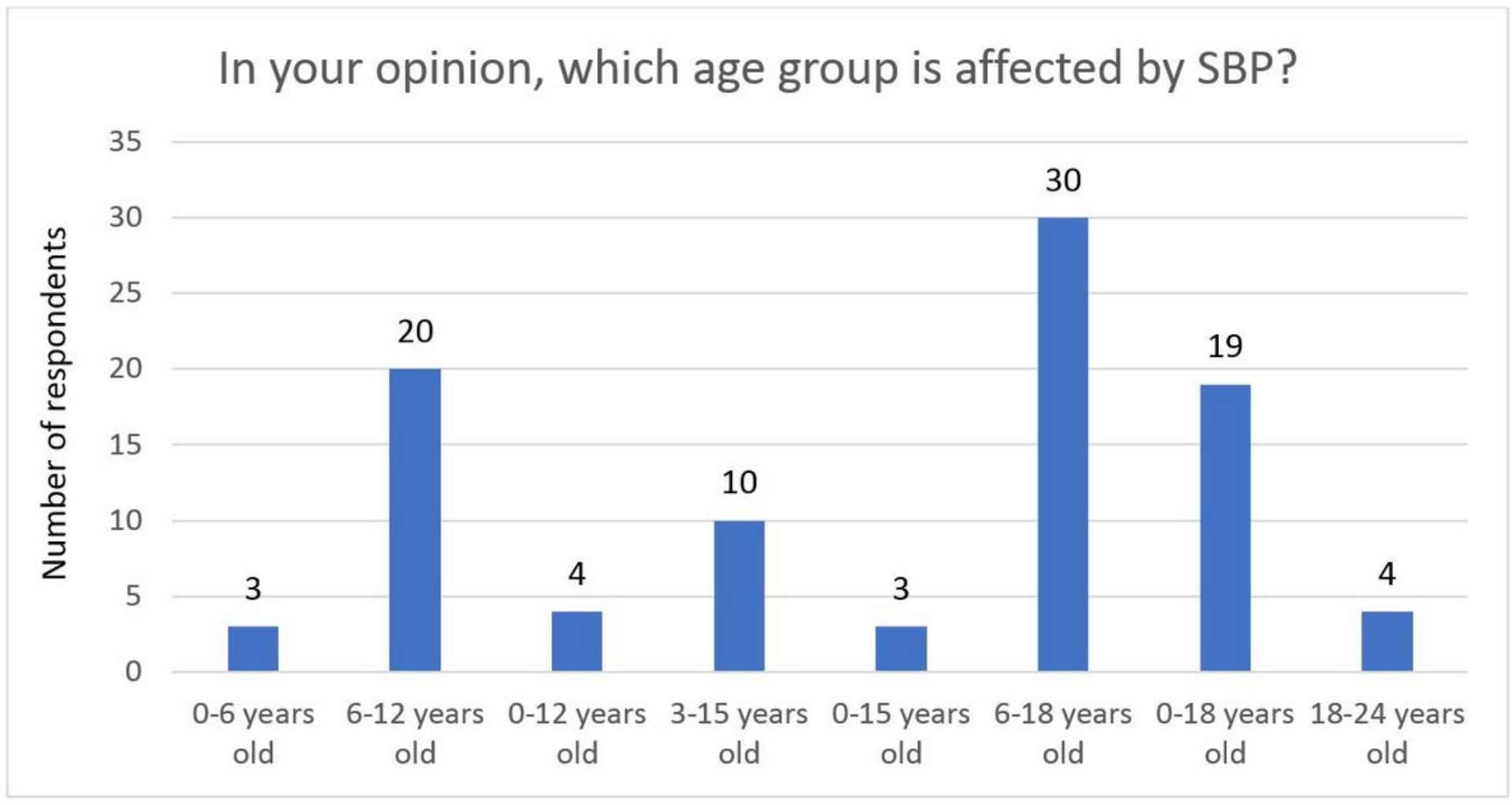


Figure 2

Representation by Professionals for the Age Group of Children Involved by SBP ( $n=93)$

\section{In your opinion, SBP}

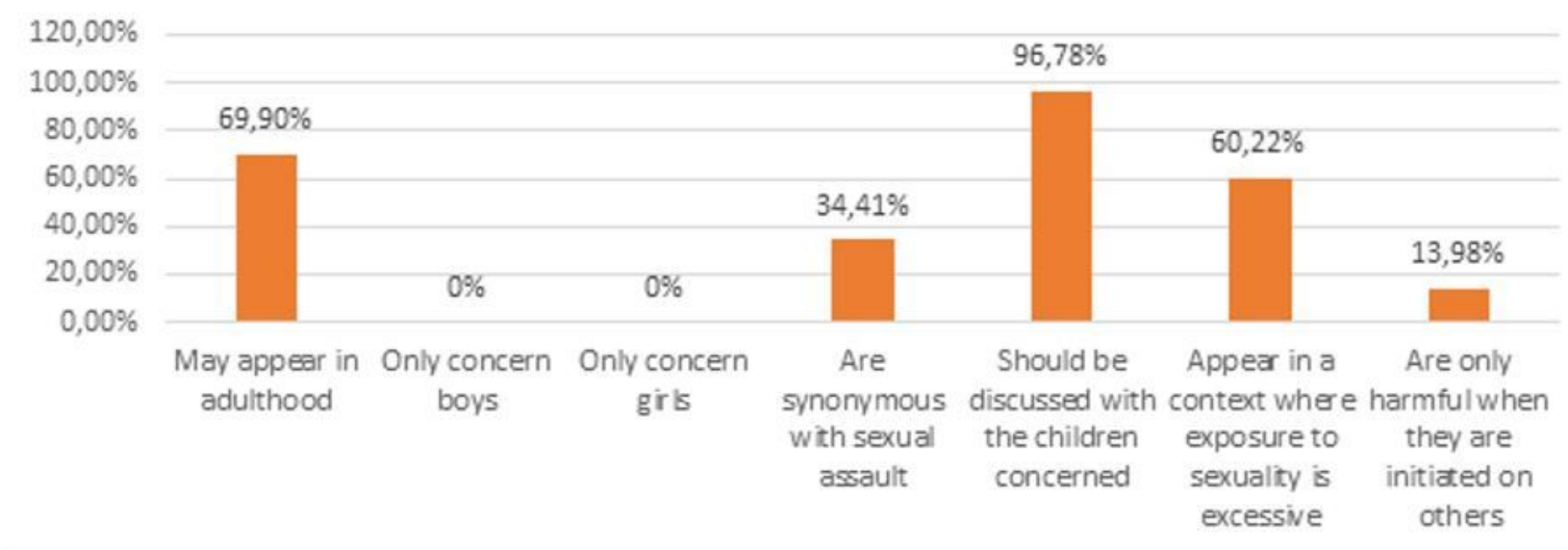

\section{In your opinion, children who exhibit SBP are children who:}

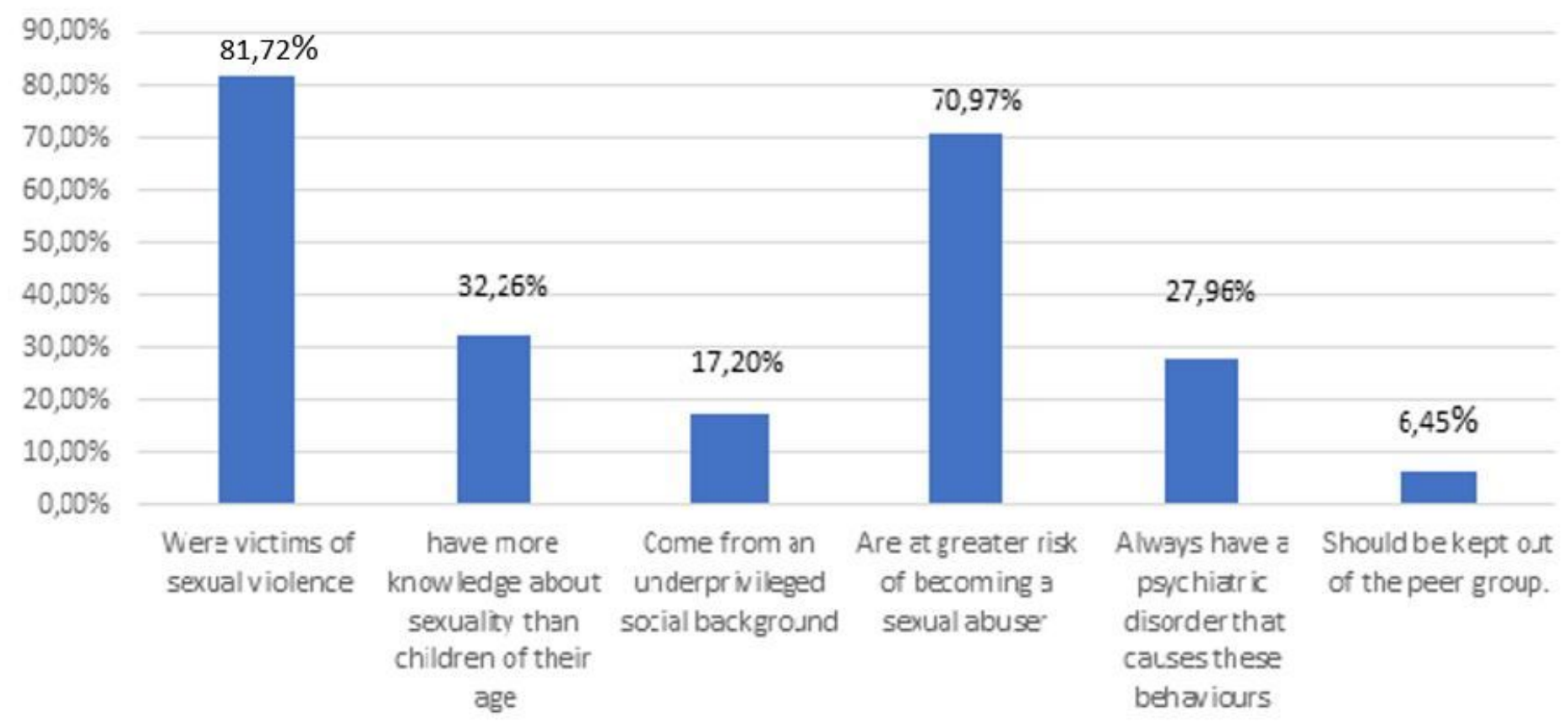

\section{Figure 3}

Representations of SBP and children with SBP by responding professionals $(n=93)$ 
In your opinion, SBP

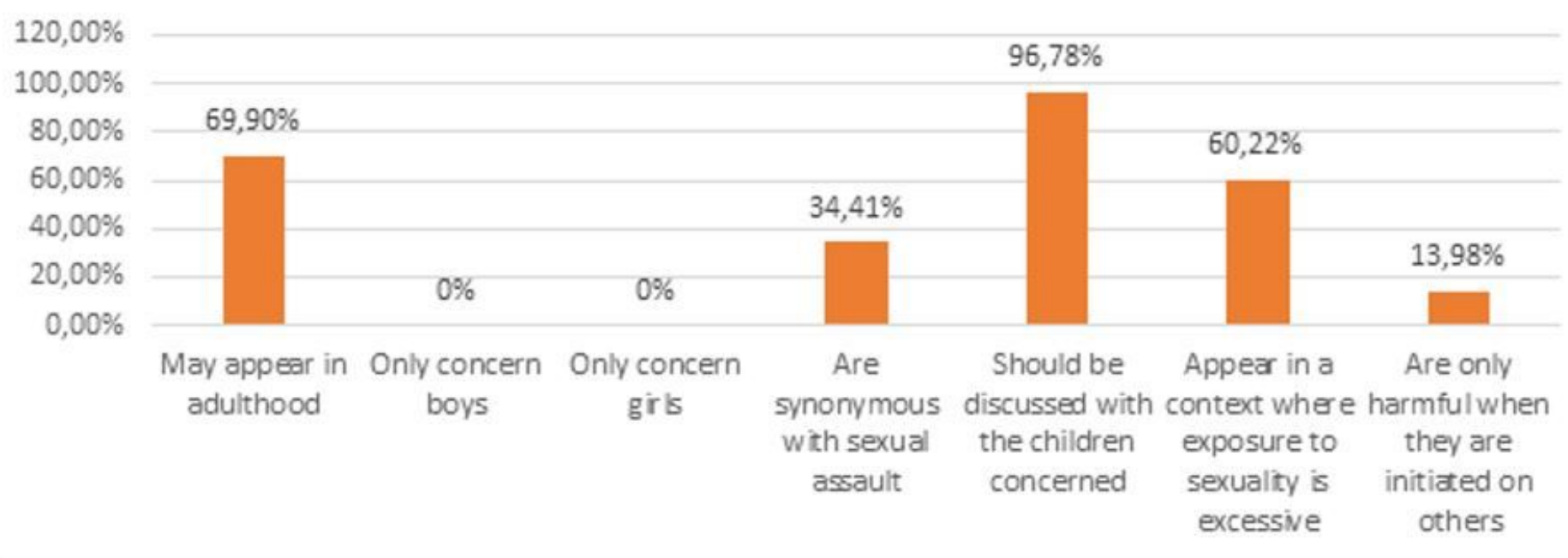

\section{In your opinion, children who exhibit SBP are children who:}

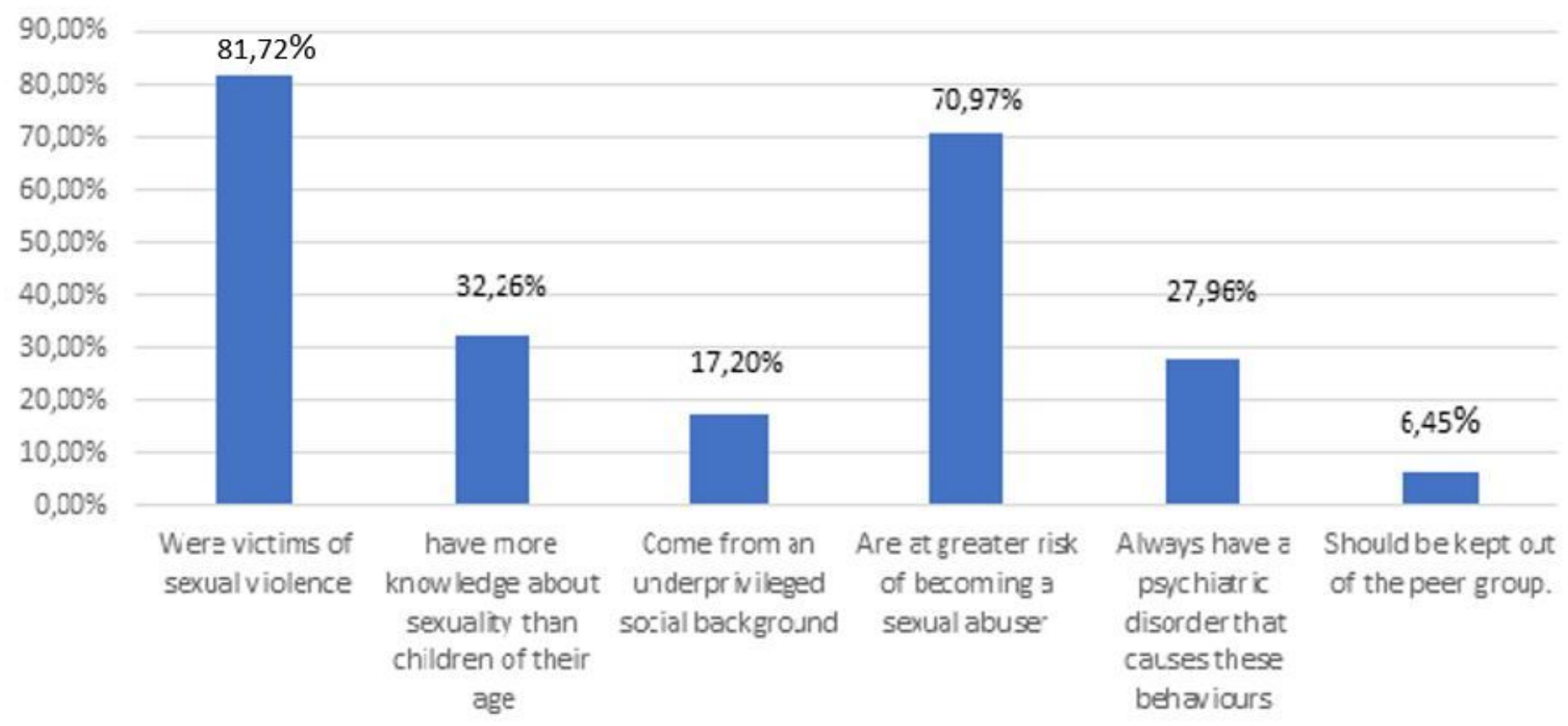

\section{Figure 3}

Representations of SBP and children with SBP by responding professionals $(n=93)$ 
In your opinion, SBP

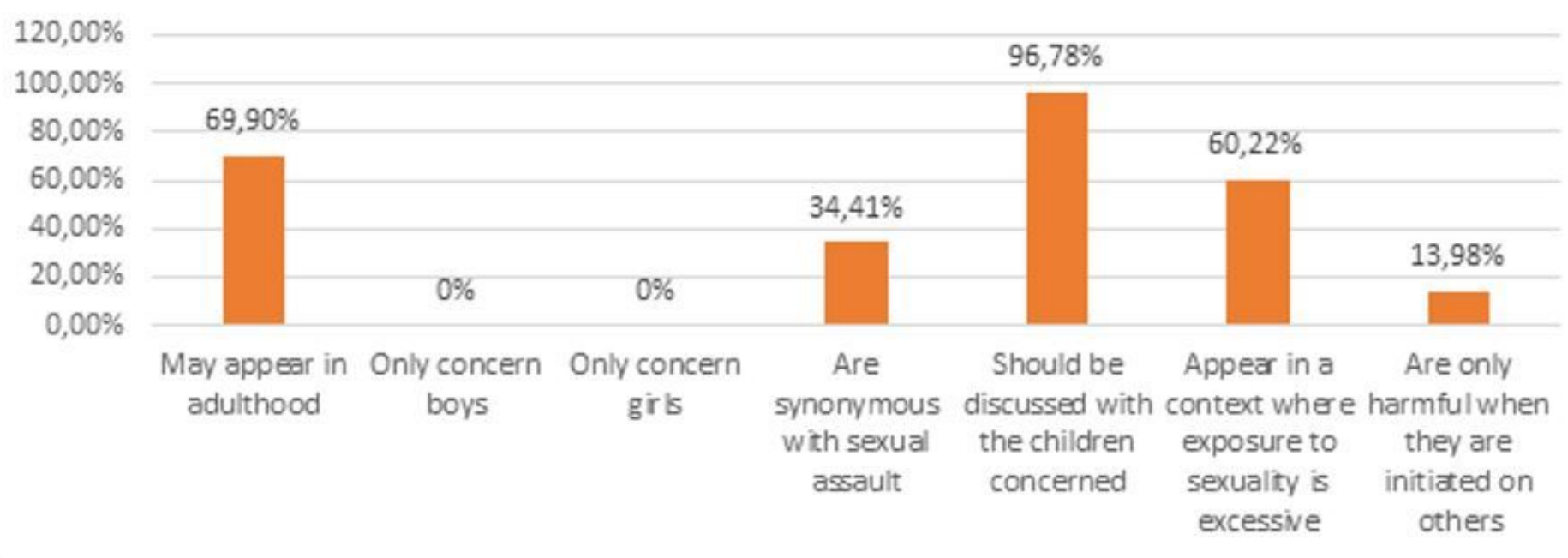

\section{In your opinion, children who exhibit SBP are children who:}

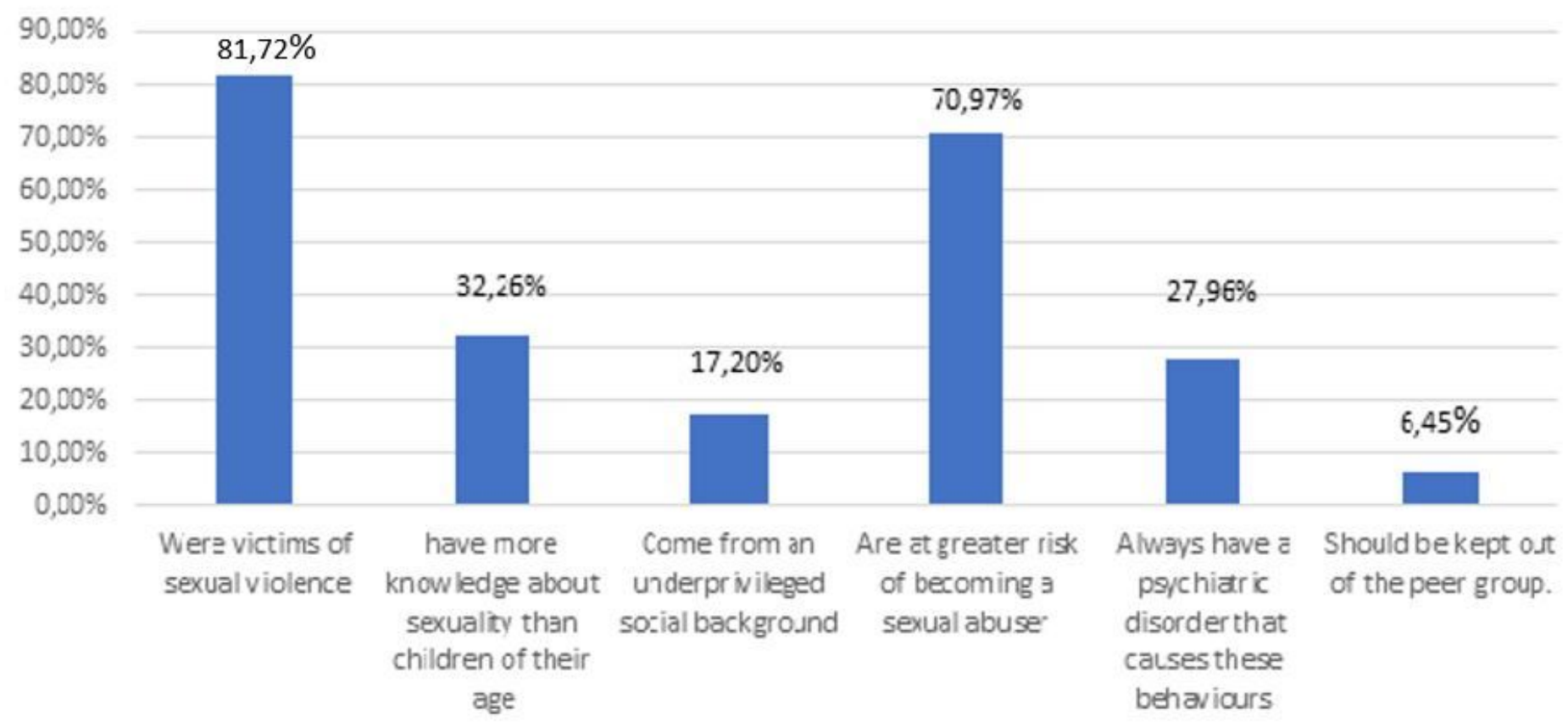

\section{Figure 3}

Representations of SBP and children with SBP by responding professionals $(n=93)$ 


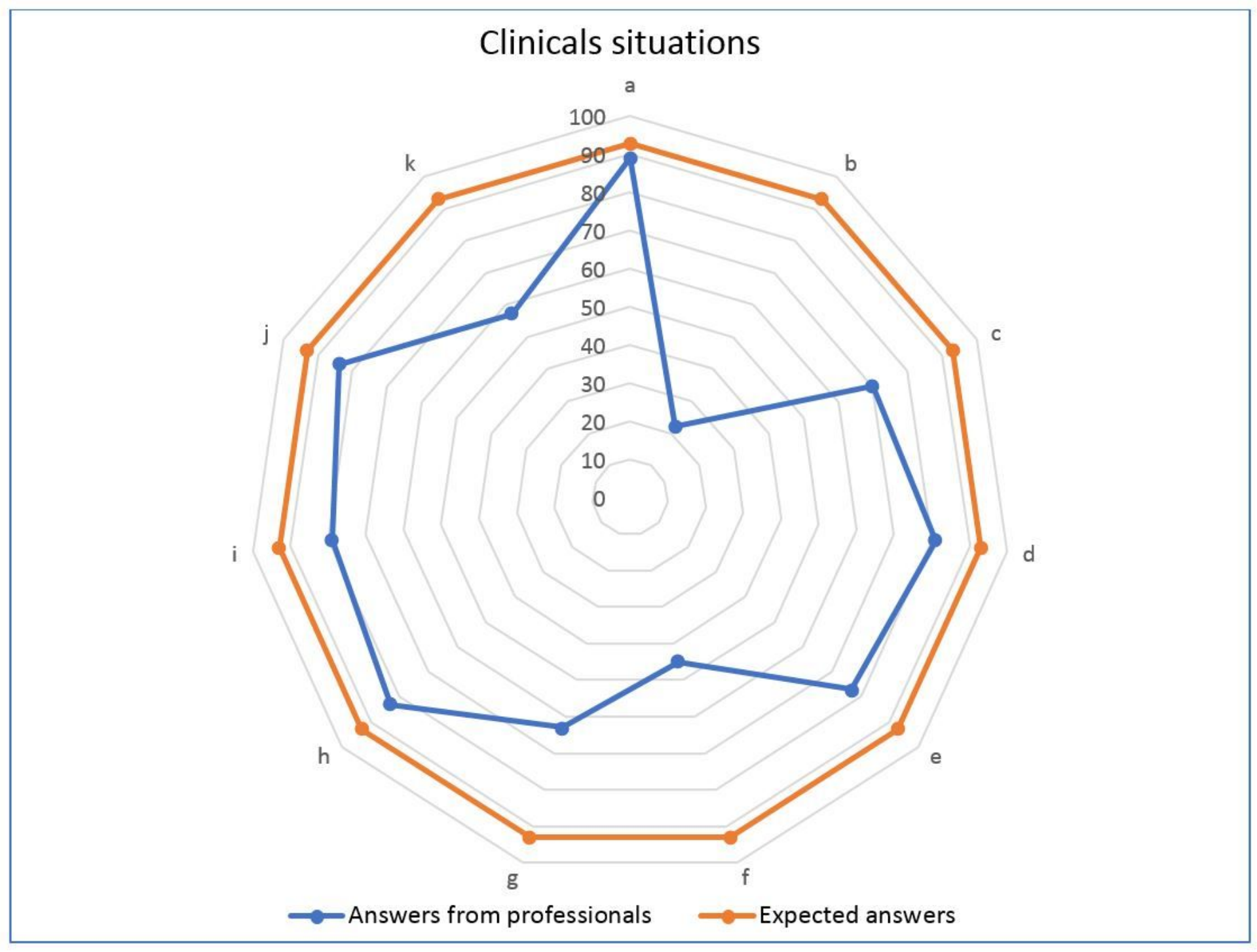

\section{Figure 4}

Representation of professionals in 11 situations judged to be either "healthy sexual behaviour" or "problematic sexual behaviour" ( $n=93$ ) Legend: a: At the age of 9 months, have an erection at the time of change a diaper b: At the age of 3 years old, insert your finger into the sexual orifice of another child c: At the age of 2 years old, lay your head on the genitals of a clothed adult $d$ : At the age of 3 years old, try to see your parents naked e: At the age of 4 years old, practice sexual games such as "the Doctor" or "daddymommy" with exploration of the other person's body or private parts $\mathrm{f}$ : At the age of 5 years old, showing off in front of others g: At the age of 7, masturbate several times a day h: At the age of 8 years old, making crude sexual comments i: At the age of 10, ask yourself about your sexual orientation $\mathrm{j}$ : At the age of 12, caressing the sexual parts of an animal k: A At the age of 14, have already had a homosexual experience (kisses, caresses, sexual relations...) 


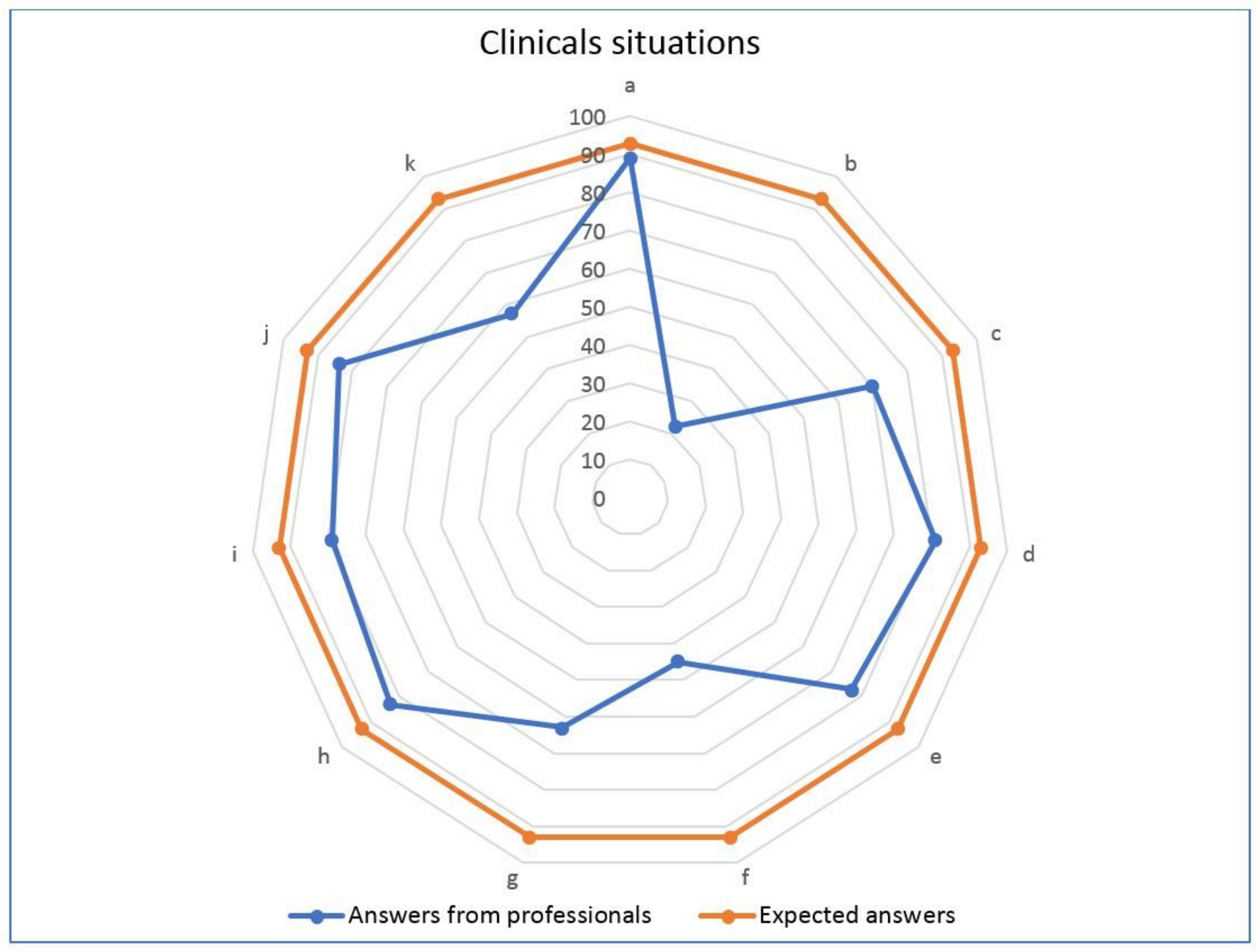

\section{Figure 4}

Representation of professionals in 11 situations judged to be either "healthy sexual behaviour" or "problematic sexual behaviour" ( $n=93$ ) Legend: a: At the age of 9 months, have an erection at the time of change a diaper b: At the age of 3 years old, insert your finger into the sexual orifice of another child c: At the age of 2 years old, lay your head on the genitals of a clothed adult $d$ : At the age of 3 years old, try to see your parents naked e: At the age of 4 years old, practice sexual games such as "the Doctor" or "daddymommy" with exploration of the other person's body or private parts $\mathrm{f}$ : At the age of 5 years old, showing off in front of others g: At the age of 7, masturbate several times a day h: At the age of 8 years old, making crude sexual comments i: At the age of 10, ask yourself about your sexual orientation $\mathrm{j}$ : At the age of 12, caressing the sexual parts of an animal k: A At the age of 14, have already had a homosexual experience (kisses, caresses, sexual relations...) 


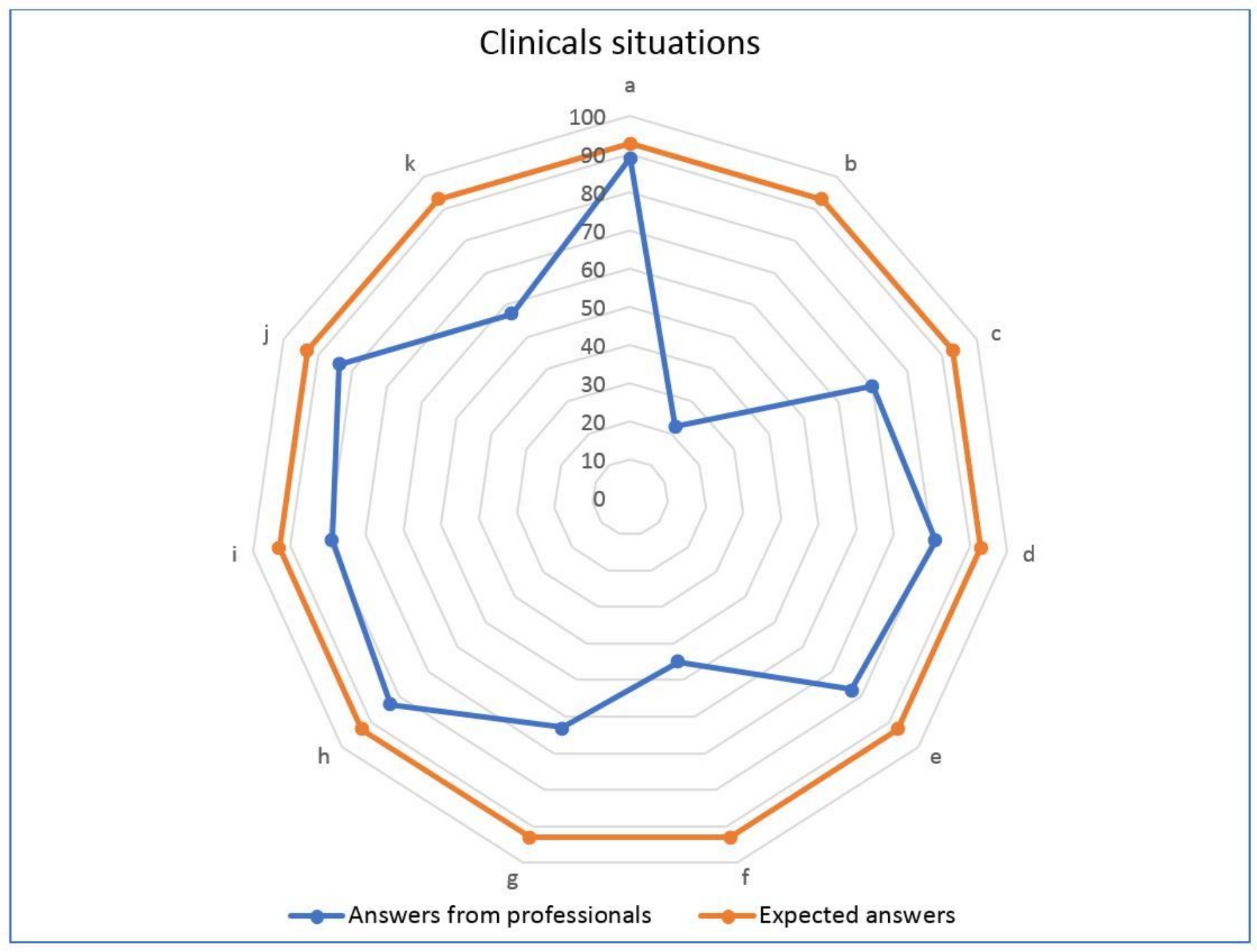

\section{Figure 4}

Representation of professionals in 11 situations judged to be either "healthy sexual behaviour" or "problematic sexual behaviour" ( $n=93$ ) Legend: a: At the age of 9 months, have an erection at the time of change a diaper b: At the age of 3 years old, insert your finger into the sexual orifice of another child c: At the age of 2 years old, lay your head on the genitals of a clothed adult $d$ : At the age of 3 years old, try to see your parents naked e: At the age of 4 years old, practice sexual games such as "the Doctor" or "daddymommy" with exploration of the other person's body or private parts $\mathrm{f}$ : At the age of 5 years old, showing off in front of others g: At the age of 7, masturbate several times a day h: At the age of 8 years old, making crude sexual comments i: At the age of 10, ask yourself about your sexual orientation $\mathrm{j}$ : At the age of 12, caressing the sexual parts of an animal k: A At the age of 14, have already had a homosexual experience (kisses, caresses, sexual relations...) 